\title{
O MARKETING SOCIAL: UM INSTRUMENTO EFICIENTE PARA O DESENVOLVIMENTO SUSTENTÁVEL DOS DESTINOS TURÍSTICOS.
}

\section{Élida Cristina Zuchini Martins ${ }^{1}$}

\author{
Rosângela C. Cortez Thomaz ${ }^{2}$
}

\section{RESUMO}

O turismo é constantemente apresentado como meio eficaz de se alcançar o desenvolvimento econômico. Porem, o que se observa, é que a falta de informação sobre o fenômeno vem permitindo o seu crescimento desordenado e causando muitos impactos negativos aos destinos e a população que reside nele. Esse artigo, através de uma pesquisa bibliográfica exploratória apresenta o marketing social como uma ferramenta eficiente para promover o desenvolvimento sustentável e a conscientização das pessoas sobre a atividade turística.

Palavras-Chave: Turismo. Marketing social. Desenvolvimento Sustentável.

INTRODUÇÃO

\footnotetext{
${ }^{1}$ Graduanda do curso de Turismo da "Universidade Estadual Paulista" - UNESP Email: elidazuchini@hotmail.com

${ }^{2}$ Pós-doutora em Turismo pela Universidade de Santiago de Compostela (USC-Espanha); Docente da faculdade de turismo da UNESP - Rosana; rocortez@rosana.unesp.br
} 
Por seu desenvolvimento massificado ser recente e por grande parte da sociedade diretamente relacioná-lo com o lazer e as férias, o turismo ainda recebe um lugar subalterno no contexto epistemológico sobre o desenvolvimento, mesmo sendo uma das atividades que mais gera renda e empregos, correspondendo a $10 \%$ do PIB mundial (entorno de US\$ 4 trilhões) e à aproximadamente 200 milhões de empregos (NUNES, 2009).

Em tese, é uma atividade passível de motivar o desenvolvimento econômico, social e cultural, além de promover melhor qualidade de vida para a comunidade local e para os turistas.

Mas, infelizmente, o que se observa, é que na realidade, o turismo tem sido visto apenas como meio de desenvolvimento econômico, atuando sem planejamento nos destinos, onde os espaços públicos vem sendo utilizados de forma desordenada.

Assim, mesmo sendo apontado como "solução" para diversas localidades, devido aos seus inúmeros benefícios, os impactos negativos da atividade turística acabam ganhando mais evidência, por aumentar índices preocupantes e transformar o modo de vida da população local.

Países em desenvolvimento e em subdesenvolvidos vêem o turismo como uma das apostas para o crescimento, e por buscarem medidas rápidas, acabam trocando projetos sustentáveis por outros que os possam proporcionar lucros em curto prazo. Desse modo acabam não se preocupando com o aproveitamento dos recursos e nem com a forma de vida da sua população.

Sancho (2001, p. 227 apud MARTINS; PEDROSA, 2004, p. 285) destaca que "alguns destinos mostram sinais de crise e estresse que exigem uma mudança de atitude dos agentes na indústria turística: as empresas, as autoridades, a população moradora e visitantes". Campanhas feitas através de técnicas mercadológicas podem se tornar eficientes para provocar uma mudança de comportamento das pessoas para minimizar os impactos negativos do turismo.

O Marketing Social é uma tecnologia da administração da mudança social que através das estratégias do marketing tradicional, promove uma causa, idéia ou um comportamento socialmente correto, e pode vir a se tornar o "provocador" para o 
comportamento responsável de turistas e autóctones que a atividade turística tanto necessita.

Esse artigo, através de uma pesquisa bibliográfica exploratória, pretende discutir sobre os problemas evidentes do turismo e através do uso da ferramenta do marketing social, mostrar o papel dos administradores públicos em promover uma mudança comportamental nos agentes envolvidos no setor turístico.

\section{TURISMO E OS IMPACTOS POSITIVOS X IMPACTOS NEGATIVOS}

A segunda metade da década de 90 foi decisiva para a globalização do turismo. $O$ mercado internacional tornou-se mais competitivo com o surgimento de novos destinos turísticos e com a valorização das praias tropicais, dos grandes espaços naturais e das áreas rurais passiveis de revivalismo das tradições, da ruralidade e dos produtos não industrializados (SIRGADO, 2003).

Portuguez (1999) destaca o turismo, atualmente, como uma das atividades sociais mais promissoras da "indústria de serviços" por ser capaz de dinamizar diversos setores produtivos em todo o mundo.

Lemos (1996 apud MARTINS; PEDROSA, 2004, p. 281) cita alguns dos efeitos positivos trazidos pelo desenvolvimento como "ligação entre povos de regiões, línguas, hábitos e gastos diferenciados; crescimento contínuo da construção e renovação das instalações turísticas; incremento nas indústrias associadas aos serviços associados ao turismo; aumento da demanda de produção agrícola, devido ao aumento do consumo; aumento de empregos; contribui na redistribuição de renda; entre outros".

Como já foi comentado no inicio desse artigo, o turismo tem estimulado o desenvolvimento, mas quando pouco ou mal planejado pode causar diversos impactos negativos que acabam se sobressaltando os positivos.

Beni (2003) elenca algumas situações desfavoráveis como: a degradação e destruição dos recursos naturais; perda da autenticidade da cultura local; descrição estereotipada e falsa do destino pelo turista, por causa da falta de informação; ausência 
de perspectivas para aqueles grupos da população local das áreas de destinação turística, que não obtém benefícios diretos das visitas dos turistas ou do próprio Sistema de Turismo da localidade; aparecimento de fenômenos de disfunção social na família, patologia no processo de socialização e desintegração da comunidade; e dependência do capital estrangeiro ou de estereótipos existentes em face do Turismo.

Pode-se acrescentar a essa lista, impactos descritos por Dias (2006), como: turismo sexual; a prostituição; transmissão de doenças sexualmente transmissíveis; uso de drogas; alcoolimo; comercialização da cultura local para o entretenimento dos visitantes; declínio da produção artística local, substituida muitas vezes por produtos industrializados; inveja e ressentimento dos moradores ao turista; alterações dos valores morais e das atitudes cotidianas. Para o autor a presença dos turistas gera mudanças visiveis nas comunidades receptoras com a alteração de comportamentos normalmente aceitos, que se chocam com os códigos morais da comunidade. (DIAS, 2006, p.25)

Martins \& Pedrosa (2004) ao decorrer de sua obra citam também a degradação do patrimônio histórico e natural; o excesso de veículos motorizados, gerando congestionamento e poluição do ar e sonora; aumento do custo de vida para os moradores; aumento da criminalidade e inflação na localidade receptora; disseminação de certos tipos de doenças; poluição da água; e destruição da fauna e da flora, provocando o desequilibro dos ecossistemas.

D'Antona (2007) ao tratar sobre turismo e comunidade local, posiciona a atividade como um componente externo que afeta negativamente as comunidades locais, pois "é um vetor poderoso das mudanças econômicas; funciona como elemento introdutor de novos hábitos; e a implantação de infra-estrutura turística chega a ter grande impacto ambiental". Alem de que, da perspectiva da geração renda, a relação com o mercado tem se mostrado desfavorável para os moradores, pois geralmente se transformam em mão de obra barata. Mas o autor observa que "tal caráter nefasto, no entanto, é somente observado, pois, são raros os lugares onde o turismo é implantado de forma sustentável e com a integração da comunidade local" (D'ANTONA, 2007, p.93)

Tantos impactos negativos poderiam ser resolvidos se os todos os agentes tivessem consciência do seu papel perante a atividade, e não se relacionassem com o 
turismo de maneira preconceituosa, cuidando de forma consciente dos espaços públicos.

Barreto (2002, p.39, apud MARTINS; PEDROSA, 2004, p. 285) tipifica duas formas de relacionamento dos usuários com os espaços públicos:

1. Privatização dos espaços públicos de uso coletivo: o usuário se apropria do espaço público;

2. Mau-trato do espaço público de uso coletivo: uso equivocado do espaço público, sujando-o ou o depredando.

Para Andrade (2006, p. 106 apud MARTINS PEDROSA, 2004, p. 283) as agressões sofridas por esses espaços são devidas a ignorância popular, que acaba fazendo com que as pessoas não valorizem o que tem de graça.

Magalhães (2002) tem observado que a insustentabilidade dos destinos é decorrente da grande indiferença quanto a adoção de medidas responsáveis escoradas no fato de que, em geral, os centros turísticos tem crescido em decorrência do aumento natural de visitantes e pela iniciativa privada de acordo com seus próprios interesses. Para a autora, "observa-se um descaso, por parte dos administradores locais, em relação a problemas do conjunto, favorecendo, em conseqüência a prosperidade de uns poucos empresários".

Martins \& Pedrosa (2004) consideram irracional e incoerente os setores do turismo trabalharem sem se preocuparem com a forma que esta sendo utilizada a praia ou como está sendo visitado determinado monumento. Eles mencionam que "nos países subdesenvolvidos e em desenvolvimento, o raciocínio em curto prazo é colocado a frente de qualquer projeto que garanta o desenvolvimento sustentável da atividade. O lucro rápido acaba deteriorando qualquer forma coletiva racional de aproveitamento dos recursos, prejudicando assim visitantes, visitados e o empresariado local." Para eles "a preservação do patrimônio natural e artificial ultrapassa o conceito de exótico e torna-se uma questão de sobrevivência para quem depende deles, principalmente localidades que sobrevivem apenas da atividade turística" (MARTINS; PEDROSA, 2004, p. 284).

Para que o turismo caminhe em busca de resultados mais satisfatórios "o planejamento turístico é uma atividade que envolve a intenção de estabelecer condições 
favoráveis para alcançar objetivos propostos" (RUSCHMANN, 1997, p. 84 apud MAGALHÃES, 2002, p. 91).

Sendo assim,

planejar para o turismo, segundo Petrocchi (1998, p. 18), é definir um futuro desejado, é contribuir para que tarefas sejam mais bem realizadas e os objetivos sejam mais facilmente atingidos, é ordenar as ações e dar prioridade a elas, é permitir mapear dificuldades e escolher caminhos alternativos (PETROCCHI, 1998, p.18 apud MAGALHÃES, 2002, p. 91)

A colaboração entre a comunidade e administradores públicos é determinante já que:

valorizar a participação da população local no processo de tomada de decisão e no planejamento integral é, nos dias atuais, uma condição sine qua non para o desenvolvimento sustentável dessa atividade. Verifica-se que na maioria das vezes os moradores querem os benefícios advindos do turismo, mas não compreendem, de forma realista, o que significa alcançá-las e quais são seus impactos, quais são as mudanças de comportamento necessárias para conservar o ambiente invés de consumi-lo predatoriamente. (MAGALHÂES, 2002, p. 90)

\title{
MARKETING SOCIAL
}

Muitas pessoas confundem o marketing com a publicidade e propaganda, mas na verdade,

\begin{abstract}
o marketing é a analise, o planejamento, a implementação e o controle de programas cuidadosamente formulados e projetados para proporcionar trocas voluntárias de valores com mercados-alvo, no propósito de atingir os objetivos organizacionais. Depende intensamente do projeto da oferta da organização em termos das necessidades e desejos dos mercados-alvo, e no uso eficaz da determinação de preço, da propaganda e da distribuição, a fim de informar, motivar e servir os mercados (KOTLER, 1978, p. 20)
\end{abstract}

Kotler (1978) destaca a troca como o conceito central do marketing, pois ele objetiva o acontecimento de trocas voluntárias de valores, onde "os especialistas de marketing procuram uma reação da outra parte, mas não uma reação que deva ser conseguida por quaisquer meios ou a qualquer preço. O marketing é a alternativa filosófica da força" (Kotler, 1978, p. 21 )

Drucker (1970 apud ALMEIDA \& BLOS, 2000) afirma que o marketing desempenha um papel-chave de desenvolvimento nas áreas de crescimento. $O$ autor 0 
constitui como um multiplicador de iniciativas. Para ele "sua implementação torna possível a integração da economia com o pleno emprego de todos os fatores ativos e da capacidade produtiva de que uma sociedade dispõe, mobilizando a energia latente e contribuindo para maior qualidade de vida" (DRUCKER, 1970 apud ALMEIDA; BLOS, 2000, p. 80)

O marketing não é apenas uma ferramenta utilizada pela iniciativa privada para "vender um produto", ele pode ser aplicado de diversas maneiras em organizações que não visam o lucro.

Cada vez mais administradores públicos estão se interessando pelas aplicações do marketing, pois se feito com um rigoroso pensamento e com planejamento adequado ele pode se tornar a solução para diversos problemas (KOTLER, 1978).

Uma das aplicações do marketing que pode ajudar o setor público é o marketing social, que utiliza as bases do marketing tradicional para promover uma mudança de postura e a aceitação de idéias socialmente responsáveis (MARTINS; PEDROSA, 2004).

No marketing social os quatro "P's" tradicionais do marketing apresentam os seguintes objetivos:

- O Produto do marketing social é o comportamento ou a oferta que o programa quer que a audiência adote; é a causa social.

- O Preço se refere aos benefícios que o público alvo da campanha terá após adotar o comportamento esperado.

-A Praça (local) é onde será exposto o programa; onde o comportamento está disponível para a audiência target; é o instrumento.

-Promoção (comunicação): é a relação da mensagem do produto com a audiência, sendo o foco a motivação das pessoas, tentando atuar sobre o comportamento; é a campanha utilizada.

No marketing social a pesquisa de mercado também é indispensável, pois se deve identificar o público que se quer atingir e o seu perfil para que se possa criar um produto de valor para aquele que compra (MARTINS; PEDROSA, 2004)

Conceituando-o: 
grupo-alvo. Utiliza-se conceitos de segmentação de mercado, de pesquisa de consumidor de configuração de idéias, de comunicações, de facilitação de incentivos e a teoria da troca, a fim de maximizar a reação do grupo-alvo (KOTLER, 1978, p. 288).

Reforçando o conceito, Araújo (2001, p.12 apud MARTINS; PEDROSA, 2004, p. 287) coloca que "o marketing social é encarado como estratégia de mudanças comportamentais e atitudinais, podendo ser utilizado em qualquer tipo de organização seja pública ou privada, lucrativa ou não, desde que tenha uma meta final de produção de transformações e impactos sociais".

Segundo Vaz (1995) o marketing social é uma modalidade de ação mercadológica institucional que tem como objetivo principal atenuar ou eliminar os problemas sociais e as carências da sociedade. Para o autor, "os programas baseados no marketing social são trabalhos cuidadosos de pesquisa, que procuram encontrar a raiz do problema social, identificando-se os focos de resistência a uma mudança (comportamental) e, então, definindo um planejamento de apresentação das idéias, de formulação das propostas e de preparação da estrutura necessária para dar sustentação à campanha" (VAZ, 1995, p. 281).

O termo marketing social apareceu no inicio da década de 70 e desde então é considerado uma tecnologia de gestão da mudança social que através de projetos devidamente planejados voltados para um ou mais grupos escolhidos como alvo pode provocar o aumento da disposição de aceitação de uma idéia ou pratica social dos mesmos.

\section{MARKETING SOCIAL E O TURISMO}

Os vários impactos negativos da atividade turística nos destinos poderiam ser evitados se todos os agentes (turistas, a comunidade, os empresários e a gestão pública) tivessem consciência sobre a atividade e utilizassem os espaços públicos e privados de forma responsável. 
Após falar sobre os impactos da atividade turística e conceituar o marketing social fica claro a relação entre ambos. O Marketing Social é uma estratégia de mudança de comportamento que pode vir a ser um provocador de uma mudança comportamental das pessoas em relação aos seus equipamentos e atrativos, pois constrói valores subjetivos que se agregam aos produtos.

É uma estratégia eficiente para ajudar na preservação das localidades, pois seu objetivo não é simplesmente educar os turistas e a comunidade local, mas causar impacto e fazer com que eles sintam a necessidade de modificar ou solidificar o seu comportamento perante atitudes socialmente responsáveis (MARTINS; PEDROSA, 2004).

Existem quatro tipos de mudanças sociais, cada uma com dificuldades variáveis e possibilidades de acontecer diferentes. É necessário identificar o problema e qual dessas mudanças poderá ajudar a solucioná-lo. Baseando-se em Kotler (1978) apresenta-se a seguir, os quatro tipos de mudanças relacionando cada uma delas com o setor turístico.

A primeira é a Mudança Cognitiva. Seu objetivo não é no sentido de modificar quaisquer atitudes ou comportamentos enraizados, mas de informar os cidadãos. São consideradas campanhas de educação pública ou campanhas de informação pública. No turismo podem ser campanhas com o objetivo de chamar a atenção para a degradação de praias, balneários, trilhas, monumentos, etc.; e campanhas para expandir o conhecimento sobre o turismo sustentável.

A segunda é a Mudança de Ação, que tentam induzir um numero máximo de pessoas a realizar uma ação específica, durante um determinado período. No turismo poderiam ser campanhas para influenciar ou atrair os turistas a escolherem um destino sustentável para passarem determinadas férias ou feriados.

A terceira é a Mudança de Comportamento, esta visa ajudar as pessoas a modificar algum aspecto de seu comportamento, tendo em vista o bem estar individual. Campanhas para convencer as pessoas a poluir e degradar menos podem ser benéficas para o turismo.

A quarta é a Mudança de Valor, que procura alterar profundamente as crenças e/ou valores que um grupo-alvo possui quanto a alguns objetos e situações. No caso do 
turismo poderiam ser campanhas para alterar as opiniões das pessoas em relação ao próprio turismo.

Para que essas mudanças obtenham os resultados esperados a escolha correta dos adotantes escolhidos como alvo seria o primeiro passo para o sucesso de qualquer proposta de mudança social: conhecimento profundo sobre o comportamento do grupo delimitado, ideologias, aspirações, enfim do modo de vida da comunidade. Esse conhecimento permite uma melhor adequação dos meios e mensagens sensibilizadores do público-alvo, despertando assim o seu interesse.

\section{CONSIDERAÇÕES FINAIS}

O turismo é um fenômeno recente e ainda é muito restrito as classes sociais mais desfavorecidas. Seus estudos são desenvolvidos por poucos estudiosos, se comparados as ciências tradicionais, e a maior parte da informação ainda não alcança a toda a população, que em sua maior parte ainda vê a palavra turismo como sinônimo de férias.

Essa falta de informação também é percebida quando se considera determinados profissionais e boa parte dos gestores da área. Em ambos as partes a maioria não tem capacitação adequada. Os gestores geralmente assumem cargos relacionados ao turismo para ocuparem uma "cadeira" no serviço público. Já a maioria dos profissionais se transforma em mão de obra barata, e com o tempo, por não encontrarem estabilidade e crescimento profissional acabam procurando emprego em outras áreas.

Se pudemos dizer que "o turismo destrói tudo o que toca", isso é decorrente da carência de informação por parte das comunidades locais e dos turistas, da falta de mãode-obra qualificada, da omissão de responsabilidade social por parte das empresas, da insuficiência de incentivo e investimentos por parte dos gestores públicos e por falta de investimentos na área da educação e em oportunidades justas para as comunidades locais, que se vêem massacradas pelos grandes investimentos hoteleiros.

O marketing social é um instrumento eficiente que pode colaborar para esse processo de mudança de postura dos agentes, promovendo praticas responsáveis, que 
preservem a cultura e o meio ambiente. Pois promover o turismo sustentável é uma maneira de tirar o prazo de validade dos destinos e de melhorar a qualidade de vida da população - que não terá mais seus espaços de uso público destruídos e poderão desenvolver novas fontes de renda- e dos visitantes - que terão mais opções de destinos e ao viajarem encontrarão locais limpos e preservados.

\section{REFERÊNCIAS}

ALMEIDA, Joaquim A.; BLOS, Wladimir. O marketing do turismo rural e o desenvolvimento sustentável. In: ALMEIDA, Joaquim A.; FROEHLICH, José M.; RIEDL, Mário (org.). Turismo rural e desenvolvimento sustentável. Campinas/SP: Papirus, 2000.

BENI, Mário Carlos. Análise estrutural do turismo. São Paulo: Senac São Paulo, 2003.

D'ANTONA, Álvaro de Oliveira. Turismo em parques nacionais. In: FUNARI, Pedro Paulo; PINSKY, Jaime. Turismo e patrimônio cultural. 4. ed. São Paulo: Contexto, 2007.

DIAS, Reinaldo. Turismo e patrimônio cultural: recursos que acompanham o crescimento das cidades. São Paulo: Saraiva, 2006.

KOTLER, Philip. Marketing para organizações que não visam lucro. São Paulo: Atlas, 1978. $430 \mathrm{p}$.

MAGALHÃES, Claudia Freitas. Diretrizes para o turismo sustentável em municípios. São Paulo: Roca, 2002.

MARTINS, Carlos Frederico Gomes; PEDROSA, Ciro Pereira. Marketing Social: Oportunidade para empresas e destinos turísticos. In: BAHL, Miguel. Turismo e Responsabilidade Social. São Paulo: Roca, 2004. Cap. 22, p. 280-292.

NUNES, Dagmar Sodré. Turismo: Um Meganegócio Mundial. Revista Turismo. Disponível em: <http://www.revistaturismo.com.br/negocios/meganegocio.htm>. Acesso em: 26 nov. 2009.

PORTUGUEZ, Anderson Pereira. Elemento para uma abordagem crítica no ensino de primeiro e segundo grau. In: RODRIGUES, Adyr Balastreri. Turismo rural e desenvolvimento sustentável. 4. ed. São Paulo: Hucitec, 1999. 


\section{Periádica Eletrânica

SIRGADO, José Rafael. Espaço turístico e o desenvolvimento no cone leste paulista. In: RODRIGUES, Adyr Balastreri. Turismo Rural: práticas e perspectivas. 2. ed. São Paulo: Contexto, 2003.

VAZ, Gil Nuno. Marketing institucional: o mercado de idéias e imagens. São Paulo: Pioneira, 1995. 